TITLE:

\title{
Cross-Coupling of Aryl Trifluoromethyl Sulfones with Arylboronates by Cooperative Palladium/Rhodium Catalysis
}

\section{$\operatorname{AUTHOR}(S)$ :}

Fukuda, Jun-Ichi; Nogi, Keisuke; Yorimitsu, Hideki

\section{CITATION:}

Fukuda, Jun-Ichi ... [et al]. Cross-Coupling of Aryl Trifluoromethyl Sulfones with Arylboronates by Cooperative Palladium/Rhodium Catalysis. Organic Letters 2019, 21(22): 8987-8991

\section{ISSUE DATE:}

2019-11-15

URL:

http://hdl.handle.net/2433/245874

\section{RIGHT:}

This document is the Accepted Manuscript version of a Published Work that appeared in final form in Organic Letters, copyright $\odot$ American Chemical Society after peer review and technical editing by the publisher. To access the final edited and published work see https://doi.org/10.1021/acs.orglett.9b03393.; The full-text file will be made open to the public on 24 October 2020 in accordance with publisher's 'Terms and Conditions for Self-Archiving'.; この論文は出版社 版でありません。引用の際には出版社版をご確認じ利用ください。; This is not the published version. Please cite only the published version. 


\title{
Cross-Coupling of Aryl Trifluoromethyl Sulfones with Arylboronates by Cooperative Palladium/Rhodium Catalysis
}

\author{
Jun-ichi Fukuda, Keisuke Nogi, and Hideki Yorimitsu* \\ Department of Chemistry, Graduate School of Science, Kyoto University, Sakyo-ku, Kyoto 606-8502, Japan
}

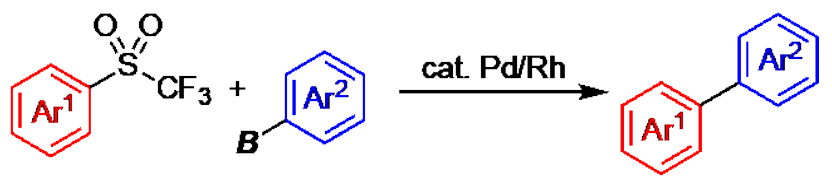

\begin{abstract}
Suzuki-Miyaura arylation of aryl trifluoromethyl sulfones via C- $\mathrm{SO}_{2}$ bond cleavage has been developed by means of cooperative palladium/rhodium catalysis. A series of aryl trifluoromethyl sulfones and arylboronic acid neopentylglycol esters are converted to the corresponding biaryls. Mechanistic investigations suggest (1) the rhodium catalyst mediates transfer of the aryl ring from arylboronate to palladium resulting in acceleration of the transmetalation step; (2) C-C-bond-forming reductive elimination step would be the turnover-limiting step.
\end{abstract}

Biaryl skeletons represent a pivotal substructure in organic chemistry and related fields including pharmaceutical and agrochemical industry as well as advanced material science. Suzuki-Miyaura cross-coupling of aryl electrophiles with arylboronic acid derivatives is among the most important methodologies for construction of biaryl skeletons. ${ }^{1}$ Besides conventional aryl halides and triflates, Suzuki-Miyaura arylation of less reactive aryl electrophiles containing $\mathrm{C}-\mathrm{F},{ }^{2} \mathrm{C}-\mathrm{O},{ }^{3}$ and $\mathrm{C}-$ $\mathrm{N}^{4,5}$ bonds has been emerging.

On the other hand, Suzuki-Miyaura arylation of aromatic organosulfur compounds has been relatively unexplored while catalytic C-S transformation has attracted much attention in the cross-coupling arena. ${ }^{6}$ As a seminal work, Liebeskind developed palladium-catalyzed arylation of arylsulfonium salts (Figure $1 \mathrm{a}$, left). ${ }^{7,8}$ Although the reaction proceeded under mild conditions due to their enhanced reactivity, the starting sulfonium salts intrinsically suffer from dealkylative decomposition. In 2002, Libeskind and Srogl accomplished Suzuki-Miyaura cross-coupling of aryl sulfides by means of a palladium catalyst and copper thiophenecarboxylate (CuTC) (Figure 1a, center). ${ }^{9,10}$ However, the applicable substrates were limited to azaaryl sulfides such as electron-deficient pyridyl and thiazolyl sulfides. Although Willis and Shi independently reported the arylation of aryl sulfides with rhodium catalysts, the reactions require carbonyl directing groups at the ortho positions (Figure 1a, right). ${ }^{11}$

To develop a new class of Suzuki-Miyaura arylation of aromatic organosulfur compounds, we focused on the use of fluorinated sulfonyl leaving group. Recently, Nambo and Crudden accomplished Suzuki-Miyaura arylation of benzyl sulfones by means of the rationally designed fluorinated sulfonyl leaving groups (Figure 1b), ${ }^{12}$ where the departing sulfinate anions would be stabilized to facilitate the $\mathrm{C}-\mathrm{SO}_{2}$ bond cleavage. Along this line, we envisioned that trifluoromethylsulfonyl $\left(\mathrm{CF}_{3} \mathrm{SO}_{2}-\right)$ group can be a suitable leaving group for Suzuki-Miyaura arylation of aryl sulfones. Here, we report Suzuki-Miyaura arylation of aryl trifluoromethyl sulfones with arylboronates (Figure 1c). Cooperative palladium/rhodium catalysis was particularly effective for efficient conversion. Mechanistic investigations suggest that the rhodium catalyst mediates the transfer of the aryl ring from arylboronates to the palladium catalyst resulting in acceleration of the transmetalation on the palladium center. During preparation of the manuscript, Moran also reported Suzuki-Miyaura arylation of aryl trifluoromethyl sulfones under palladiumRuPhos catalysis (Figure 1d). ${ }^{13}$

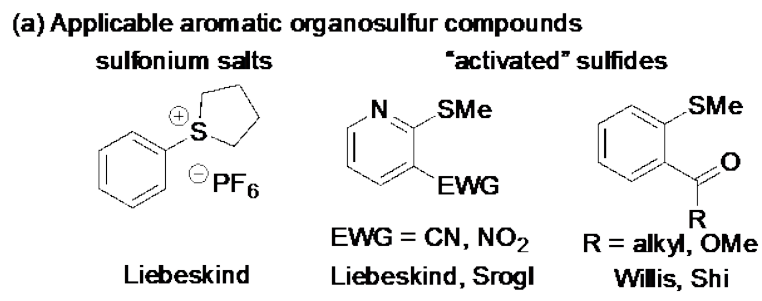

(b) Arylation of benzyl sulfones using fluorinated sulfonyl groups (Nambo, Crudden)

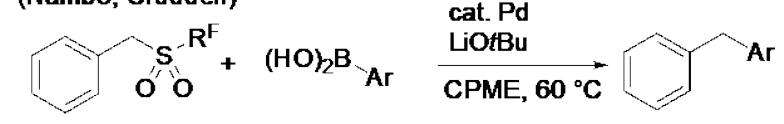

$\mathrm{R}^{\mathrm{F}}=\mathrm{CF}_{3}, 3,5-\left(\mathrm{CF}_{3}\right)_{2} \mathrm{C}_{6} \mathrm{H}_{3}$

(c) This Work

Arylation of aryl trilluoromethyl sulfones by means of $\mathrm{Pd} / \mathrm{Rh}$ catalysis

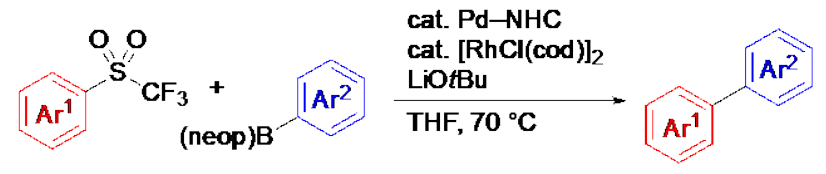

(d) Moran's recent work

Pd-catalyzed arylation with arylboronic acids

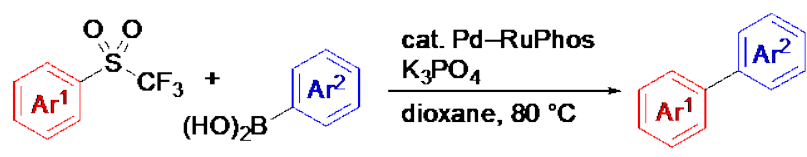

Figure 1. Suzuki-Miyaura arylation of organosulfur compounds.

We chose the reaction of phenyl trifluoromethyl sulfone (1a) with 4-methoxyphenylboronic acid neopentylglycol ester (2a) as a model reaction. Because Pd-NHC ( $N$-heterocyclic carbene) complexes showed good catalytic activity in our previous $\mathrm{C}-\mathrm{S}$ 
transformations, ${ }^{6 \mathrm{~d}}$ we performed the reaction with $10 \mathrm{~mol} \%$ of Pd-PEPPSI-IPr (See Figure 2 for the structures of ligands and metal complexes) in the presence of $\mathrm{LiOtBu}$ as a base. While desired biaryl 3aa was formed, the yield was only $27 \%$, and $56 \%$ of sulfone 1a was recovered (Table 1, entry 1 ).

To facilitate the reaction, we next attempted the addition of a metal co-catalyst to the reaction system because previous $\mathrm{Su}-$ zuki-Miyaura arylations of azaaryl sulfides require the addition of CuTC $^{9}$ (See Table S1 for details of the evaluation of co-catalysts). The thiophilic copper salt would interact with the thiolate anion on the palladium catalyst resulting in acceleration of the transmetalation process. Although the use of CuTC and copper-phosphine complexes lowered the yield of 3aa, $10 \mathrm{~mol} \%$ of $\mathrm{CuCl}(\mathrm{IPr})$ increased the yield to $40 \%$ (Table 1, entries 2-4). Gratifyingly, in place of copper, rhodium complexes showed good catalytic activities; employment of $[\mathrm{RhCl}(\mathrm{cod})]_{2}$ and $[\mathrm{Rh}(\mathrm{OH})(\mathrm{cod})]_{2}$ gave 3 aa in $75 \%$ and $74 \%$ yields, respectively (entries 5 and 6). On the other hand, $[\mathrm{RhCl}(\mathrm{nbd})]_{2}$ (nbd $=$ norbornadiene) was less effective for the reaction, and no 3aa was obtained with $\mathrm{RhH}\left(\mathrm{PPh}_{3}\right)_{4}$ (entries 7 and 8).

Table 1. Evaluation of co-catalysts

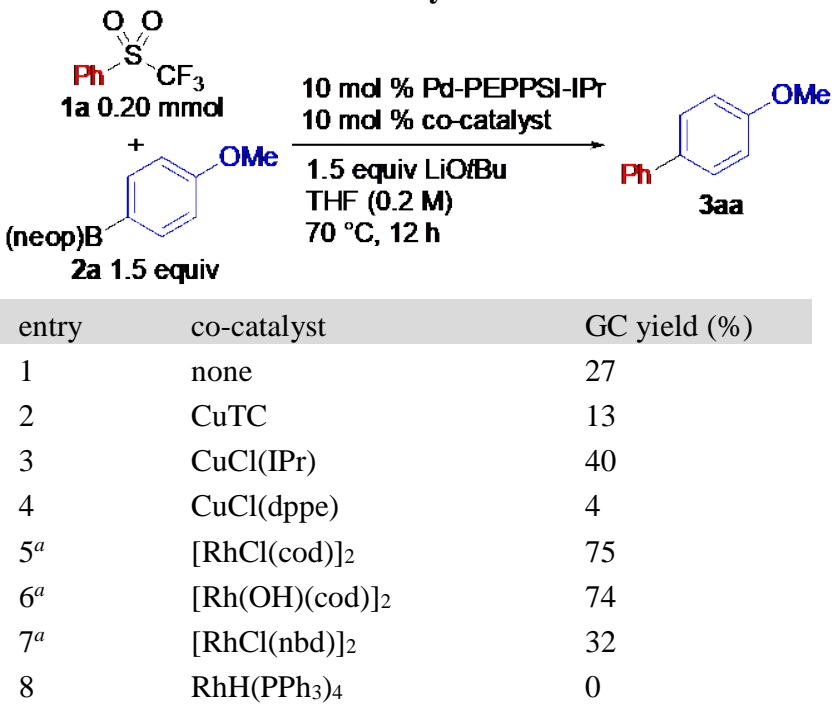

${ }^{a} 5 \mathrm{~mol} \%$ of co-catalyst was used.

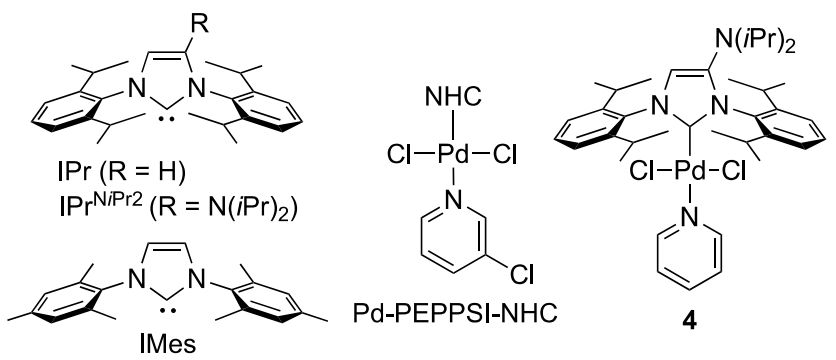

Figure 2. Structures of ligands and catalysts.

With $[\mathrm{RhCl}(\mathrm{cod})]_{2}$ as the optimal co-catalyst, we continued the optimization study with lower catalyst loadings: $2.5 \mathrm{~mol} \%$ of a palladium catalyst and $1.3 \mathrm{~mol} \%$ of $[\mathrm{RhCl}(\mathrm{cod})]_{2}$ (Table 2, See Table S2 for details of the screening of palladium catalysts). When Pd-PEPPSI-IPr was employed, 3aa was obtained in $40 \%$ yield, although Pd-PEPPSI-IMes entirely shut down the reaction (entries 1 and 2). To our delight, diisopropylamino-substituted IPr (IPr $\left.{ }^{\mathrm{NiPr} 2}\right)^{14}$ was found to be highly effective; the yield of 3aa was considerably improved to $85 \%$ by means of IPr ${ }^{N i P r}$ ligated palladium complex 4 (entry 3). The choice of the counter cation of bases has great impact on the yield of the product, and the yields of 3aa significantly dropped with $\mathrm{NaOtBu}$ and $\mathrm{KOtBu}$ (entries 4 and 5). Unfortunately, milder bases such as $\mathrm{LiOAc}$, and $\mathrm{Li}_{2} \mathrm{CO}_{3}$ were not suitable for this reaction whereas CsF afforded 3aa in a moderate yield (entries 6-8). Eventually, 3aa was obtained in 91\% isolated yield under more concentrated conditions $(0.5 \mathrm{M})$ (entry 9$)$. Naturally, the absence of palladium catalyst 4 did not give the product at all (entry 10). The use of the rhodium co-catalyst again proved to be important for high yield of the product; 3aa was obtained in 52\% yield in the absence of $[\mathrm{RhCl}(\mathrm{cod})]_{2}$ (entry 11). We also tested other arylboron reagents instead of $\mathbf{2 a}$. Although 4- $\mathrm{MeOC}_{6} \mathrm{H}_{4} \mathrm{~B}(\mathrm{OH})_{2}$ could also be used for the reaction, the use of the corresponding pinacol ester, 4- $\mathrm{MeOC}_{6} \mathrm{H}_{4} \mathrm{~B}$ (pin), resulted in a much lower yield of 3aa (entries 12 and 13). ${ }^{15}$

Table 2. Screening of Conditions

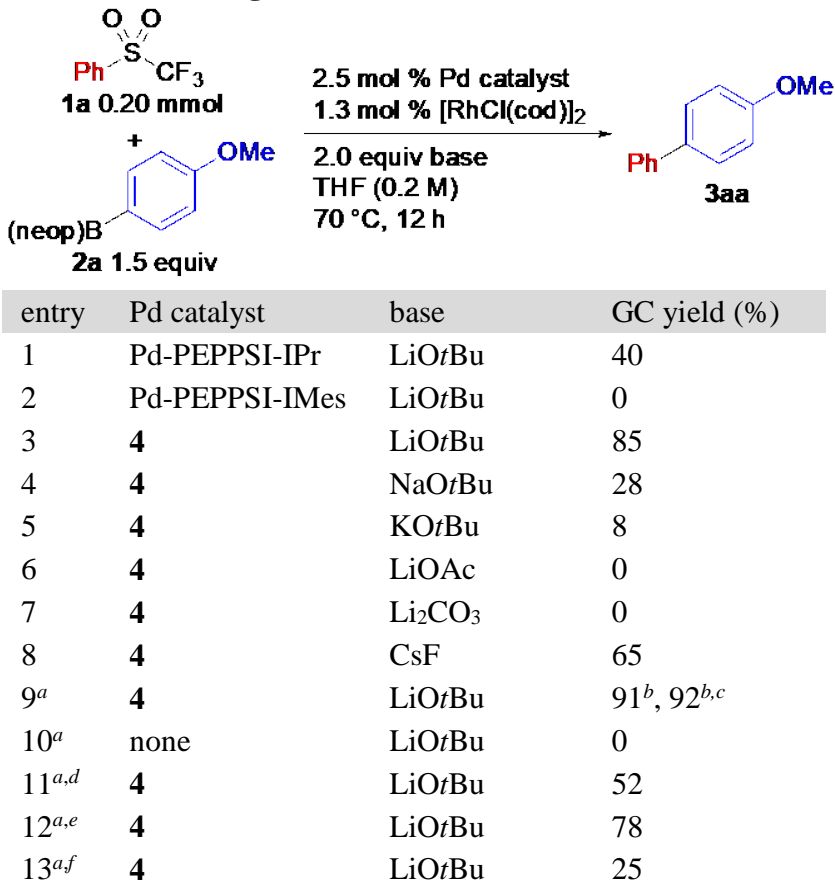

${ }^{a}$ Concentration: 0.5 M. ${ }^{b}$ Isolated yield. ${ }^{c} 2.0 \mathrm{mmol}$ scale. ${ }^{d}$ Without $[\mathrm{RhCl}(\mathrm{cod})]_{2}$. ${ }^{e} 4-\mathrm{MeOC}_{6} \mathrm{H}_{4} \mathrm{~B}(\mathrm{OH})_{2}$ instead of 2 a. ${ }^{f_{4}}$ MeOC ${ }_{6} \mathrm{H}_{4} \mathrm{~B}$ (pin) instead of $\mathbf{2 a}$.

Having the optimized conditions in hand (Table 2, entry 9), the reaction scope with respect to aryl trifluoromethyl sulfones $\mathbf{1}$ was investigated (Scheme 1a). Electron-rich 4-methoxyphenyl sulfone $\mathbf{1 b}$ underwent the arylation while higher catalyst loadings (5.0 mol \% of $\mathbf{4}$ and $2.5 \mathrm{~mol} \%$ of [RhCl(cod) $]_{2}$ ) were necessary for a high yield of the product. Several functional groups including siloxy, fluoro, benzoyl, and tert-butyl ester were compatible with the present arylation to yield biaryls 3ca-fa. Unfortunately, methylsulfanyl-substituted phenyl sulfone $\mathbf{1 g}$ did not undergo the reaction resulting in quantitative recovery of $\mathbf{1 g}$. Deactivated palladium thiolate species might be formed via the C-SMe cleavage resulting in no turnover of the palladium catalyst. The methyl group at the ortho-position of $\mathbf{1 h}$ did not hamper the reaction to afford 3ha in $85 \%$ yield. 2-Naphthyl sulfone $\mathbf{1 i}$ uneventfully took part in the arylation to provide $3 \mathbf{i a}$. 
Scheme 1. Scope of arylation

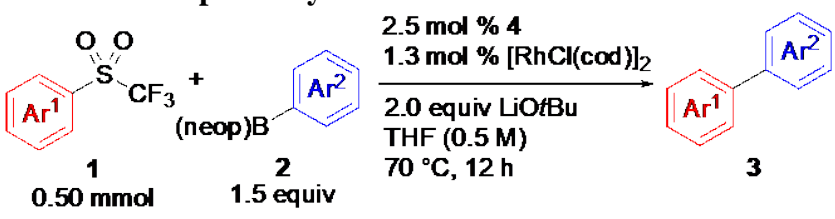

(a) With respect to aryl sulfones 1
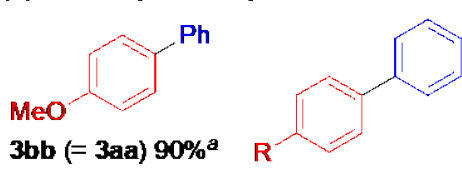

\section{OMe}

$\mathrm{R}=\mathrm{OSifBuMe}_{2}(\mathbf{3 c a}): 83 \%$ $F$ (3da): COPh (3ea): $\mathrm{CO}_{2} \mathrm{fBu}(3 \mathrm{fa})$ SMe (3ga):<smiles>COc1ccc(-c2ccccc2C)cc1</smiles>

3ha $85 \%$

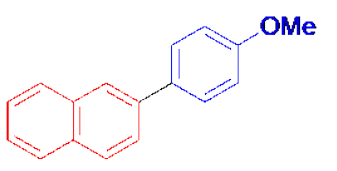

3ia $81 \%$ (b) With respect to aryl- and alkenylboronates 2

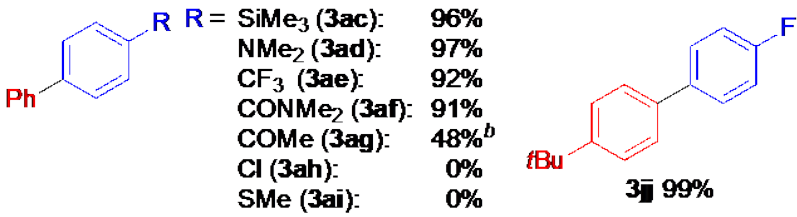<smiles>Cc1ccccc1-c1ccccc1</smiles>

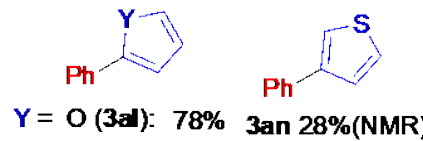
$S$ (3am): $0 \%$

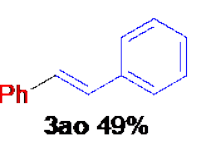

${ }^{a} 5.0 \mathrm{~mol} \%$ of 4, $2.5 \mathrm{~mol} \%$ of $[\mathrm{RhCl}(\mathrm{cod})]_{2}, 24$ h. ${ }^{b} \mathrm{LiOH} \cdot \mathrm{H}_{2} \mathrm{O}$ instead of $\mathrm{LiOtBu}$.

The reaction scope with respect to arylboronates 2 was then explored (Scheme 1b). Both electron-rich and -poor arylboronates underwent the present arylation to afford the desired biaryls in high yields. The trimethylsilyl group on 2c was also tolerated; desired product 3ac was obtained in 96\% yield. Employment of arylboronate $\mathbf{2 g}$ having an acetyl moiety resulted in the formation of a $31 \%$ yield of 3ag under the standard conditions. Degradation of the acetyl group by strongly basic $\mathrm{LiOtBu}$ was thought to be problematic. The use of $\mathrm{LiOH} \cdot \mathrm{H}_{2} \mathrm{O}$ as a milder base improved the yield of 3ag to 48\%. 4-Chlorophenylboronate $\mathbf{2 h}$ did not participate in the reaction; $\mathbf{2 h}$ would be consumed by polymerization via the $\mathrm{C}-\mathrm{Cl}$ bond cleavage. The methylsulfanyl group on arylboronate $\mathbf{2} \mathbf{i}$ was detrimental to the reaction, and both of aryl sulfone $\mathbf{1} \mathbf{a}$ and arylboronate $\mathbf{2} \mathbf{i}$ were recovered after the reaction. Deactivation of the palladium catalyst via the C-SMe cleavage would be problematic (vide supra). The reaction with ortho-substituted arylboronate $\mathbf{2 k}$ proceeded efficiently to give 2-methyl-1,1'-biphenyl (3ak) in 82\% yield. The use of 2-furylboronate $2 \mathbf{l}$ did not retard the reaction and 2phenylfuran (3al) was obtained in 78\% yield, whereas 2- or 3thienylboronate $\mathbf{2 m}$ or $\mathbf{2 n}$ failed to be applied to the arylation. Not only arylboronates, trans-2-phenylvinylboronate 20 also undergo the reaction to furnish trans-stilbene (3ao) in a moderate yield.
Scheme 2. Reactions of aryl sulfones bearing sulfonyl groups other than trifluoromethylsulfonyl group.

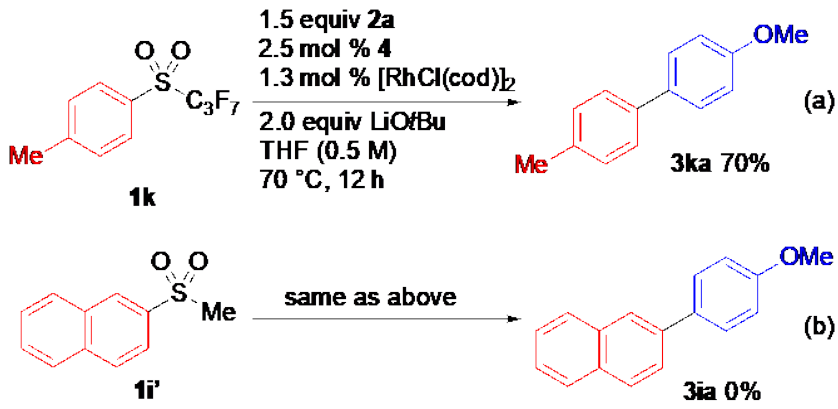

Instead of trifluoromethyl sulfones, heptafluoropropyl sulfone $\mathbf{1 k}$ could be employed for the arylation, and desired product 3ka was obtained in $70 \%$ yield (Scheme $2 \mathrm{a}$ ). Perfluorinated sulfonyl groups proved to be essential for the reaction; no biaryl 3ia was obtained from methyl 2-naphthyl sulfone (1i') resulting in quantitative recovery of 1i' (Scheme $2 b$ ).

As shown in Table 1 , the addition of $[\mathrm{RhCl}(\mathrm{cod})]_{2}$ as the cocatalyst dramatically promotes the present arylation. To learn about the effect of the rhodium catalyst, we assessed the kinetic profile of the arylation in the presence (4: $2.5 \mathrm{~mol} \%$, $\left.[\mathrm{RhCl}(\mathrm{cod})]_{2}: 1.3 \mathrm{~mol} \%\right)$ or the absence (4: $\left.5.0 \mathrm{~mol} \%\right)$ of the rhodium catalyst. As shown in Figure 3, initial reaction rate $\left(r_{0}\right)$ of the co-catalyzed system (red) was much higher than that of the reaction without $[\mathrm{RhCl}(\mathrm{cod})]_{2}$ (blue). These results demonstrate the acceleration effect of the rhodium catalyst. Moreover, significantly longer induction period (until $50 \mathrm{~min}$ ) was observed in the absence of $[\mathrm{RhCl}(\operatorname{cod})]_{2}$, which implies that the rhodium catalyst would facilitate generation of active $\operatorname{Pd}(0)$ species from precatalyst 4 .

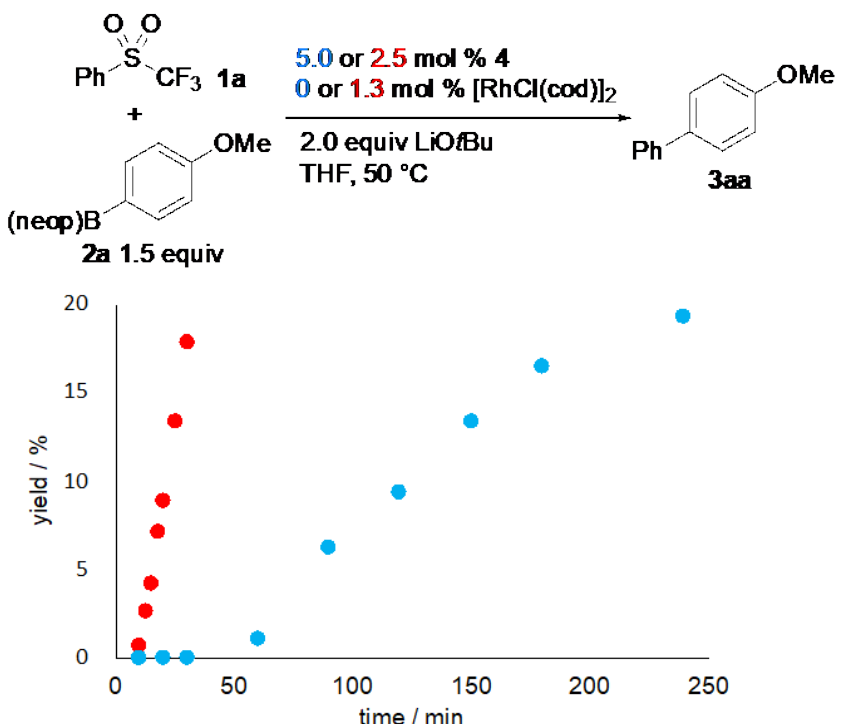

Figure 3. Time profiles of the yields of 3aa with (red) or without (blue) $[\mathrm{RhCl}(\mathrm{cod})]_{2}$ (with Rh: $2.5 \mathrm{~mol} \%$ of 4 and $1.3 \mathrm{~mol} \%$ of $[\mathrm{RhCl}(\mathrm{cod})]_{2}$; without Rh: $5.0 \mathrm{~mol} \%$ of $\left.\mathbf{4}\right)$.

Rhodium complexes readily react with arylboronates to generate arylrhodium species. ${ }^{16}$ We thus hypothesized that $[\mathrm{RhCl}(\mathrm{cod})]_{2}$ would mediate transfer of the aryl ring from arylboronate to the palladium catalyst to accelerate the transmetalation step on the palladium center. 
Scheme 3. Possible catalytic cycle of $\mathbf{P d} / \mathbf{R h}$-co-catalyzed cross-coupling.

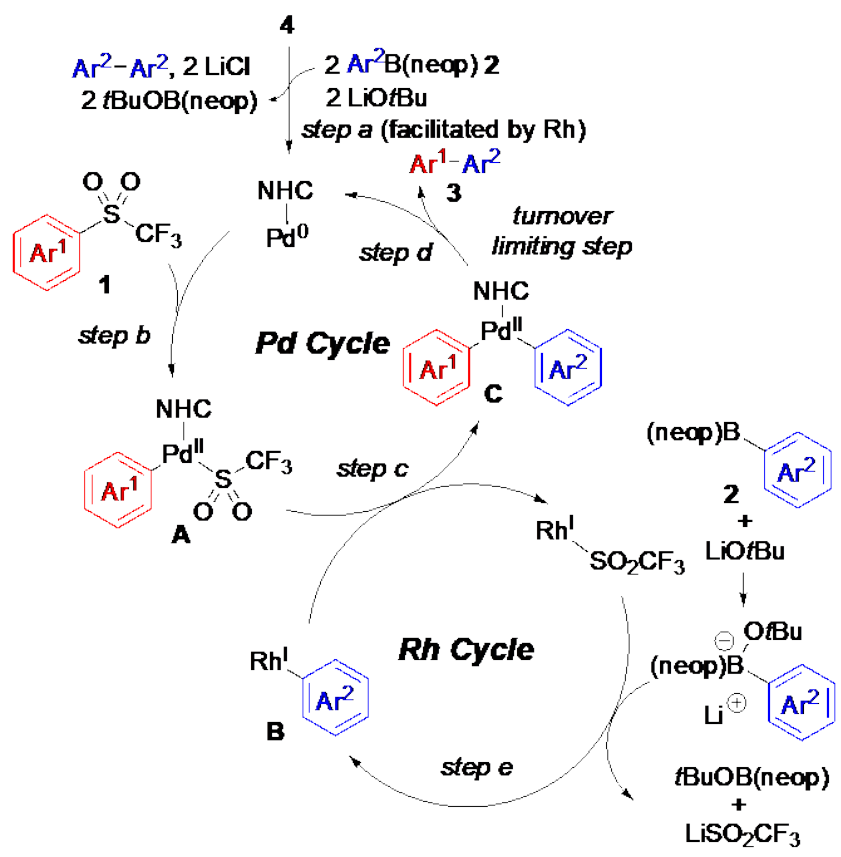

A possible mechanism based on this hypothesis is depicted in Scheme 3. First, palldium precatalyst 4 would be reduced to $\operatorname{Pd}(0)$ via two-fold transmetalation with 2 and subsequent reductive elimination (step $a$ ) because a much shorter induction period was observed in the presence of $[\mathrm{RhCl}(\mathrm{cod})]_{2}$ (Figure 3 , red). We assume that the rhodium catalyst would accelerate the transmetalation step resulting in rapid generation of the $\operatorname{Pd}(0)$ species. Aryl trifluoromethyl sulfone $\mathbf{1}$ undergoes oxidative addition with the $\operatorname{Pd}(0)$ species to afford arylpalladium(II) A (step b). Intermediate $\mathbf{A}$ would go through transmetalation with arylrhodium $\mathbf{B}$ generated from $\mathrm{Rh}(\mathrm{I})$ species and arylboronate $\mathbf{2}$ with the aid of $\mathrm{LiOtBu}$ to provide diarylpalladium $\mathbf{C}$ (step c). Finally, reductive elimination from $\mathbf{C}$ furnishes coupling product 3 with regeneration of $\mathrm{NHC}-\mathrm{Pd}(0)$ (step $d$ ).

To gain further insight into the transmetalation step, we then measured $r_{0}$ while changing the initial concentrations of $2 \mathbf{a}$ and $\mathrm{LiOtBu}$ (See Figures S3-S5 for details). ${ }^{17}$ In the presence of $[\mathrm{RhCl}(\mathrm{cod})]_{2}$, under the concentrations studied, $r_{0}$ of the reaction was estimated to almost zero-order in the initial concentration of 2a ([2a $\left.]_{0}\right)$ (Figure 4, red). ${ }^{18,19}$ The transmetalation step between arylpalladium $\mathbf{A}$ and arylrhodium $\mathbf{B}$ (Scheme 3, step c) would not be a turnover-limiting step. Conversely, in the absence of the rhodium catalyst, the plotting of $r_{0}$ against [2a $]_{0}$ showed a positive dependence under the concentrations studied (Figure 4, blue). The reaction would be approximately 1.6 thorder in $[\mathbf{2 a}]_{0}$, which intimates that the transmetalation between palladium and arylboronate would be the turnover-limiting step in the absence of $[\mathrm{RhCl}(\mathrm{cod})]_{2}$. These indicate the intermediacy of the rhodium catalyst for rapid transfer of the aryl ring from arylboronate to the palladium catalyst.

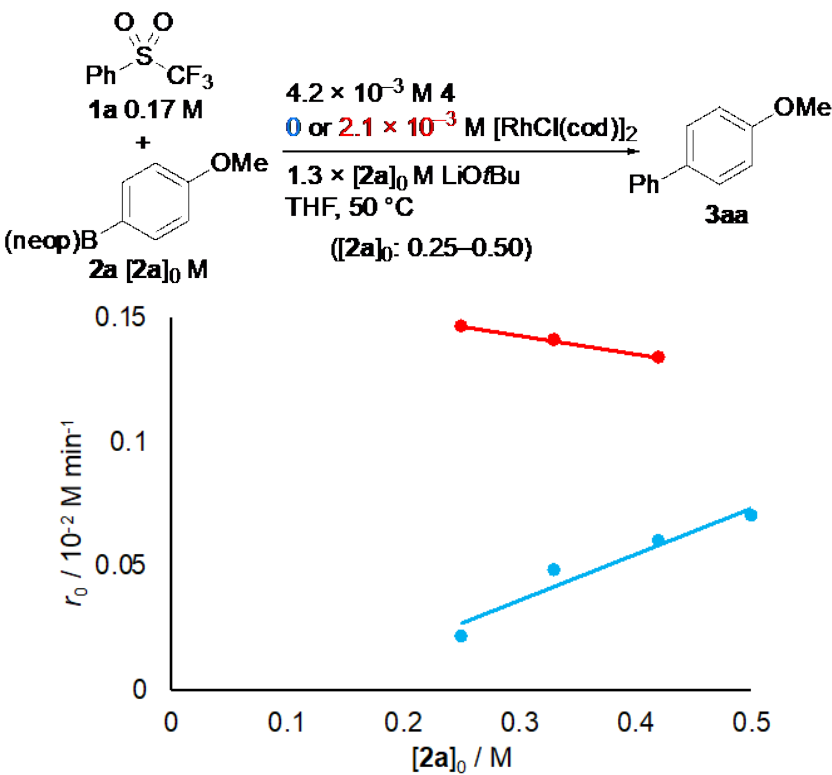

Figure 4. Plots of initial reaction rate $\left(r_{0}\right)$ against $[\mathbf{2 a}]_{0}$ with (red) or without (blue) $[\mathrm{RhCl}(\mathrm{cod})]_{2}$.

We also measured $r_{0}$ against the initial concentrations of $\mathbf{1 a}$ $\left([\mathbf{1 a}]_{0}\right)$ and $[\mathrm{RhCl}(\mathrm{cod})]_{2}\left([\mathbf{R h}]_{0}\right)$, respectively (See Figures S1, S2, S8, and S9 for details). Under the concentrations studied, it turned out that $r_{0}$ was almost zero-order in $[\mathbf{1 a}]_{0}$ and $[\mathbf{R h}]_{0}$, respectively. These results imply that neither of the steps, oxidative addition of $\mathbf{1}$ (Scheme 3, step $b$ ) nor generation of arylrhodium B (Scheme 3, step e) would be a turnover-limiting step.

On the other hand, the plotting of $r_{0}$ against the initial concentration of palladium precatalyst $4\left([4]_{0}\right)$ showed positive dependence and the reaction was estimated to nearly 1st-order in $[4]_{0}$ (See Figures S6 and S7 for details). These observations are consistent with the turnover-limiting step would be the reductive elimination step to afford biaryls $\mathbf{3}$ (Scheme 3 , step $d$ ). César found that bulky IPr ${ }^{\mathrm{NiPr} 2}$ ligand facilitates the C-N-bondforming reductive elimination resulting in acceleration of the Buchwald-Hartwig amination with bulky tertiary amines. ${ }^{14}$ In a similar fashion, IPr ${ }^{\mathrm{NiPr} 2}$ ligand would accelerate the turnover limiting reductive elimination step, the $\mathrm{Pd}-\mathrm{IPr}^{\mathrm{NiPr} 2}$ complex thus showed the highest catalytic activity in our arylation.

Based on their mechanistic and computational studies, Moran et al. suggested that oxidative addition of the $\mathrm{C}-\mathrm{S}$ bond of an aryl trifluoromethyl sulfone to a $\mathrm{Pd}(0)-\mathrm{RuPhos}$ complex would be the turnover-limiting step in their system. ${ }^{13}$ On the other hand, in our system, electron-rich $\mathrm{IPr}^{\mathrm{NiPr} 2}$ ligand would accelerate the $\mathrm{C}-\mathrm{S}$ cleavage, thus the oxidative addition would not be a turnover-limiting step.

In conclusion, we have developed Suzuki-Miyaura arylation of aryl trifluoromethyl sulfones under cooperative palladium/rhodium catalysis. The arylation herein presented accommodates a series of aryl trifluoromethyl sulfones as well as arylboronates to give the corresponding biaryls in moderate to excellent yields. Kinetic measurements indicate (1) the rhodium catalyst mediates transfer of the aryl ring from arylboronate to palladium resulting in acceleration of the transmetalation on the palladium center; (2) C-C-bond-forming reductive elimination step would be the turnover-limiting step that would be accelerated by IPrNiPr2 ligand.

\section{ASSOCIATED CONTENT}




\section{Supporting Information}

Experimental procedures, kinetic measurements, and spectral data. This material is available free of charge via the Internet at http://pubs.acs.org.

\section{AUTHOR INFORMATION}

\section{Corresponding Author \\ *yori@kuchem.kyoto-u.ac.jp \\ Notes}

The authors declare no competing financial interest.

\section{ACKNOWLEDGMENT}

This work was supported by JSPS KAKENHI Grant Numbers JP16H04109, JP18H04254，JP18H04409，JP19H00895， and JP18K14212.

\section{REFERENCES}

(1) (a) Miyaura, N.; Suzuki, A. Chem. Rev. 1995, 95, 2457. (b) Miyaura, N. Bull. Chem. Soc. Jpn. 2008, 81, 1535. (c) Suzuki, A. Angew. Chem. Int. Ed. 2011, 50, 6722.

(2) Reviews: (a) Amii, H.; Uneyama, K. Chem. Rev. 2009, 109, 2119. (b) Ohashi, M.; Ogoshi, S. Catalysts 2014, 4, 321. (c) Ahrens, T.; Kohlmann, J.; Ahrens, M.; Braun, T. Chem. Rev. 2015, 115, 931. (d) Ohashi, M.; Ogoshi, S. J. Synth. Org. Chem., Jpn. 2016, 74, 1047.

(3) Selected reviews: (a) Rosen, B. M.; Quasdorf, K. W.; Wilson, D. A.; Zhang, N.; Resmerita, A.-M.; Garg, N. K.; Percec, V. Chem. Rev. 2011, 111, 1346. (b) Mesganaw, T.; Garg, N. K. Org. Process Res. Dev. 2013, 17, 29. (c) Tobisu, M.; Chatani, N. Top. Organomet. Chem. 2013, 44, 35. (d) Yamaguchi, J.; Muto, K.; Itami, K. Eur. J. Org. Chem. 2013, 19. (e) Han, F.-S. Chem. Soc. Rev. 2013, 42, 5270. (f) Cornella, J. Zarate, C.; Martin, R. Chem. Soc. Rev. 2014, 43, 8081.

(4) (a) Blakey, S. B.; MacMillan, D. W. C. J. Am. Chem. Soc. 2003, 125, 6046. (b) Ueno, S.; Chatani, N.; Kakiuchi, F. J. Am. Chem. Soc. 2007, 129, 6098. (c) Koreeda, T.; Kochi, T.; Kakiuchi, F. J. Am. Chem. Soc. 2009, 131, 7238. (d) Cao, Z.-C.; Xie, S.-J.; Fang, H.; Shi, Z.-J. J. Am. Chem. Soc. 2018, 140, 13575.

(5) For the Suzuki-Miyaura arylaton of nitroarenes via $\mathrm{C}-\mathrm{NO}_{2}$ bond cleavage, see: (a) Yadav, M. R.; Nagaoka, M.; Kashihara, M.; Zhong, R.-L.; Miyazaki, T.; Sakaki, S.; Nakao, Y. J. Am. Chem. Soc. 2017, 139, 9423. (b) Chen, K.; Chen, W.; Yi, X.; Chen, W.; Liu, M.; Wu, H. Chem. Commun. 2019, 55, 9287. (c) Kashihara, M.; Zhong, R.-L.; Semba, K.; Sakaki, S.; Nakao, Y. Chem. Commun. 2019, 55, 9291.

(6) For recent reviews, see: (a) Wang, L.; He, W.; Yu, Z. Chem. Soc. Rev. 2013, 42, 599. (b) Modha, S. G.; Mehta, V. P.; van der Eycken, E. V. Chem. Soc. Rev. 2013, 42, 5042. (c) Pan, F.; Shi, Z.-J. ACS Catal. 2014, 4, 280. (d) Gao, K.; Otsuka, S.; Baralle, A.; Nogi, K.; Yorimitsu, H.; Osuka, A. J. Synth. Org. Chem., Jpn. 2016, 74, 1119. (e) Otsuka, S.; Nogi, K.; Yorimitsu, H. Top. Curr. Chem. 2018, 376, 13.

(7) Srogl, J.; Allred, G. D.; Liebeskind, L. S. J. Am. Chem. Soc. 1997, 119,12376
(8) Related C-S-cleaving reactions of sulfonium salts with organoboron compounds: (a) Zhang, S.; Marshall, D.; Liebeskind, L. S. J. Org. Chem. 1999, 64, 2796. (b) Lin, H.; Dong, X.; Li, Y.; Shen, Q.; Lu, L. Eur. J. Org. Chem. 2012, 4675. (c) Vasu, D.; Yorimitsu, H.; Osuka, A. Angew. Chem. Int. Ed. 2015, 54, 7162. (d) Vasu, D.; Yorimitsu, H.; Osuka, A. Synthesis 2015, 47, 3286. (e) Minami, H.; Otsuka, S.; Nogi, K.; Yorimitsu, H. ACS Catal. 2018, 8, 579. (f) Berger, F.; Plutschack M. B.; Riegger, J.; Yu, W.; Speicher, S.; Ho, M.; Frank, N.; Ritter, T. Nature 2019, 567, 223.

(9) Liebeskind, L. S.; Srogl, J. Org. Lett. 2002, 4, 979.

(10) Related works on Suzuki-Miyaura coupling of activated organosulfur compounds: (a) Liebeskind, L. S.; Srogl, J. J. Am. Chem. Soc. 2000, 122, 11260. (b) Savarin, C.; Srogl, J.; Liebeskind, L. S. Org. Lett. 2001, 3, 91. (c) Yu, Y.; Liebeskind, L. S. J. Org. Chem. 2004, 69, 3554.

(11) (a) Hooper, J. F.; Young, R. D.; Pernik, I.; Weller, A. S.; Willis, M. C. Chem. Sci. 2013, 4, 1568. (b) Pan, F.; Wang, H.; Shen, P.-X.; Zhao, J.; Shi, Z.-J. Chem. Sci. 2013, 4, 1573.

(12) (a) Nambo, M.; Crudden, C. M. Angew. Chem. Int. Ed. 2013, 53, 742. (b) Nambo, M.; Keske, E. C.; Rygus, J. P. G.; Yim, J. C.-H.; Crudden, C. M. ACS Catal. 2017, 7, 1108. Related works: (c) Ariki, Z. T.; Maekawa, Y.; Nambo, M.; Crudden, C. M. J. Am. Chem. Soc. 2018, 140, 78. (d) Nambo, M.; Tahara, Y.; Yim, J. C.-H.; Crudden, C. M. Chem. Eur. J. 2019, 25, 1923. (e) Yim, J. C. H.; Nambo, M.; Tahara, Y.; Crudden, C. M. Chem. Lett. 2019, 48, 975.

(13) Chatelain, P.; Sau, A.; Rowley, C. N.; Moran, J. Angew. Chem. Int. Ed. 2019, 58, 14959.

(14) Zhang, Y.; Lavigne, G.; Lugan, N.; César, V. Chem. Eur. J. 2017, 23, 13792.

(15) The substituents on the boron atoms of arylboron compounds dramatically affect Suzuki-Miyaura cross-coupling. Thomas, A. A.; Zahrt, A. F.; Delaney, C. P.; Denmark, S. E. J. Am. Chem. Soc. 2018, $140,4401$.

(16) Selected examples of rhodium-catalyzed transformations of organoboron compounds: (a) Sakai, M.; Hayashi, H.; Miyaura, N. Organometallics 1997, 16, 4229. (b) Takaya, Y.; Ogasawara, M.; Hayashi, T.; Sakai, M.; Miyaura, N. J. Am. Chem. Soc. 1998, 120, 5579. Direct observation of arylrhodium species from arylboronic acids: (c) Hayashi, T.; Takahashi, M.; Takaya, Y.; Ogasawara, M. J. Am. Chem. Soc. 2002, 124, 5052. (d) Zhao, P.; Incarvito, C. D.; Hartwig, J. F. J. Am. Chem. Soc. 2007, 129, 1876.

(17) The measurements of the $r_{0}$ was conducted after the induction periods.

(18) In the presence of the Rh catalyst, the aryl transfer from arylboronate to the Rh would be sufficiently fast. Therefore, under the concentration studied, it can be consistent that a considerable y intercept is observed.

(19) In the present cross-coupling, homo-coupling of arylboronates 2 to the corresponding biaryls was observed as a side reaction. The homo-coupling was accelerated by increasing $[\mathbf{2 a}]_{0}$ because this process can be 2 nd order in [2a $]_{0}$. The palladium and rhodium catalysts would be involved not only in the cross-coupling but also in the competing homo-coupling, which resulted in apparent deceleration of the cross-coupling by increasing [2a $]_{0}$. The slightly negative slope of the plot would be consistent with these considerations. 